\title{
Clinical significance of hypertension in patients with different types of cancer treated with antiangiogenic drugs (Review)
}

\author{
MEI DONG ${ }^{1 *}$, RUJIAN WANG ${ }^{2 *}$, PING SUN $^{2}$, DONGXIA ZHANG ${ }^{1}$, \\ ZHENZHEN ZHANG ${ }^{1}$, JING ZHANG ${ }^{1}$, GARY TSE $^{3}$ and LIN ZHONG $^{1}$
}

\begin{abstract}
Departments of ${ }^{1}$ Cardiology and ${ }^{2}$ Oncology, The Affiliated Yantai Yuhuangding Hospital of Qingdao University, Yantai, Shandong 264000; ${ }^{3}$ Tianjin Key Laboratory of Ionic-Molecular Function of Cardiovascular Disease, Department of Cardiology, Tianjin Institute of Cardiology, Second Hospital of Tianjin Medical University, Tianjin 300211, P.R. China
\end{abstract}

Received August 23, 2020; Accepted January 13, 2021

DOI: $10.3892 / \mathrm{ol} .2021 .12576$

\begin{abstract}
Hypertension is a common comorbidity in patients receiving antiangiogenic therapy. Prior studies have reported worsening or new-onset hypertension as an adverse event of antiangiogenetic therapy, which can be managed by dose reduction or discontinuation of the culprit medication. By contrast, other studies have found that the occurrence of hypertension is a potential biomarker associated with greater efficacy of antiangiogenic therapy and predicts improved survival. At present, there is no consensus on the effects of hypertension in patients treated with antiangiogenic drugs. The present study reviewed the relationship between antiangiogenic drugs and hypertension in different types of cancer. It was demonstrated that the use of antiangiogenic drugs was associated with an increased risk of hypertension in most types of solid cancers. There was no significant difference in the incidence of hypertension between monoclonal antibody and small-molecule tyrosine kinase inhibitor treatments. Hypertension was more likely to occur in patients younger than 75 years old, female, and those with no history of bevacizumab use. Discontinuation or death caused by hypertension was rare, although previous studies have reported that hypertension was a risk factor for acute and chronic cardiovascular diseases and ischemic stroke. Of note, the early development of hypertension may serve as a potential
\end{abstract}

Correspondence to: Dr Lin Zhong, Department of Cardiology, The Affiliated Yantai Yuhuangding Hospital of Qingdao University, 20 Yuhuangding East Road, Yantai, Shandong 264000, P.R. China E-mail: yizun1971@126.com

Dr Gary Tse, Tianjin Key Laboratory of Ionic-Molecular Function of Cardiovascular Disease, Department of Cardiology, Tianjin Institute of Cardiology, Second Hospital of Tianjin Medical University, 23 Pingjiang Road, Tianjin 300211, P.R. China

E-mail: gary.tse@doctors.org.uk

${ }^{*}$ Contributed equally

Key words: anti-angiogenic drugs, hypertension, cancers, biomarker, clinical significance biomarker associated with greater efficacy of antiangiogenic therapy.

\section{Contents}

1. Introduction

2. Relationship between antiangiogenic therapy and hypertension in renal cell cancer

3. Relationship between antiangiogenic therapy and hypertension in gastric and gastroesophageal junction cancers

4. Relationship between antiangiogenic therapy and hypertension in lung cancer

5. Relationship between antiangiogenic therapy and hypertension in colorectal cancer

6. Relationship between antiangiogenic therapy and hypertension in hepatocellular carcinoma

7. Relationship between antiangiogenic therapy and hypertension in breast cancer

8. Discussion

9. Conclusion

\section{Introduction}

Angiogenesis is a crucial enabling process for tumor growth and metastasis (1). The vascular endothelial growth factor (VEGF) signaling pathway serves a key role in the angiogenesis of solid tumors. The VEGF signaling system is complex and consists of five related ligands: VEGF-A, VEGF-B, VEGF-C, VEGF-D and placental growth factor (PLGF). They bind with different specificities to three receptor tyrosine kinases: VEGFR1, VEGFR2 and VEGFR3 (2). VEGF pathway-targeting agents include monoclonal antibodies, such as bevacizumab and ramucirumab, and small-molecule tyrosine kinase inhibitors (TKIs), such as sunitinib, sorafenib, apatinib and regorafenib. Monoclonal antibodies block the binding of VEGF to VEGFR and prevent activation of intracellular signal transduction (3). Small-molecule TKIs act on the intracellular domain of the endothelial receptor, where they inhibit the initial phosphorylation step following the ligand-receptor interaction (4). These drugs can slow down the growth of tumors effectively 
and improve the progression-free survival (PFS) and overall survival (OS) of patients with cancer (2).

However, a previous study has reported that antiangiogenic therapy increased arterial blood pressure (BP), raised the risk of new-onset hypertension, or worsened existing hypertension (5). The mechanism underlying the antiangiogenic drug-induced hypertension remains controversial. The current hypotheses include decreased nitric oxide (NO) (6), increased endothelin-1 (7), capillary rarefaction (8) and activation of the renin-angiotensin-aldosterone system (RAAS) (9) (Fig. 1). According to the National Cancer Institute's common terminology criteria for adverse events (NCI CTCAE), version 5.0 (10), hypertension for adults can be classed into five categories depending on its severity (Table I). Subsequently, the presence of hypertension can lead to a reduction or interruption of antiangiogenic therapy (11).

Considering the complex relationship between antihypertensive drugs and cancer, the cancer type, the pre-existing comorbidities and the presence of contraindications should be considered when selecting antihypertensive drugs for patients with cancer (12). Currently, angiotensin-converting enzyme inhibitors (ACEIs) are the preferred first-line option in treatment of hypertension induced by anti-VEGF chemotherapy, given its improved outcome in several types of cancer (13). On the other hand, several retrospective studies $(14,15)$ have found that the appearance of hypertension during antiangiogenic therapy might be associated with improved survival. Thus, it remains unclear whether hypertension should be considered as an adverse reaction or as a positive prognostic marker in patients with various types of cancer. The present review aimed to explore the relationship between hypertension and antiangiogenic therapy in different types of tumors.

\section{Relationship between antiangiogenic therapy and hy- pertension in renal cell cancer}

In total, nine studies have reported the association between hypertension and antiangiogenic drugs, including sunitinib, bevacizumab, sorafenib, axitinib and pazopanib, in renal cell carcinoma (RCC). Of these nice studies, seven were prospective studies (16-22) and two were retrospective studies $(23,24)$, involving a total of 6,083 patients (Table II).

Hypertension as an adverse event of antiangiogenic therapy. Four phase III, randomized, double-blind, placebo-controlled trials $(16-18,20)$ and a phase II, randomized, double-blind trial (19) demonstrated that antiangiogenic drugs increased the risk of hypertension in patients with RCC. Increased BP due to axitinib gradually dropped to baseline after the end of treatment (19). The incidence of hypertension in the TKI treatment group (33.2\%) was higher compared with the group treated with monoclonal antibodies $(27.4 \%)$. It is worth noting that the axitinib group had the highest incidence of severe hypertension [ $\geq$ grade $(\mathrm{G}) 3$ hypertension]. Compared with the aforementioned studies, hypertension was more frequently observed in the Donskov et al study (24), which could be attributed to the different definition of hypertension used. Furthermore, the risk of hypertension may be dose-dependent (19), however, no association with nephrectomy was observed (16). Thus, further research is needed to provide more evidence for the association between antiangiogenic treatment and the risk of hypertension in patients with RCC.

Hypertension as a biomarker of antiangiogenic therapy. Two studies $(22,23)$ found that significant hypertension $(\geq G 2)$ may be a potential biomarker associated with greater efficacy. In addition, another study using real-world data from Japan demonstrated that patients with hypertension have a higher 24-week OS and PFS rate (21). Donskov et al (24) found that on-treatment hypertension is an independent biomarker of sunitinib efficacy. These studies did not report the median time of hypertension-onset. However, Goldstein et al (25) found that hypertension caused by pazopanib or sunitinib was not a biomarker in the treatment of metastatic RCC.

3. Relationship between antiangiogenic therapy and hypertension in gastric cancer and gastroesophageal junction cancers

As an adjuvant treatment of gastric cancer, antiangiogenic drugs significantly prolong the survival of patients with advanced or metastatic gastric cancer (GC) in addition to gastroesophageal junction carcinoma (GEJ), and hypertension is a common adverse reaction that cannot be ignored. Five studies have reported the association between hypertension and antiangiogenic drugs, including apatinib and ramucirumab, of which, four were prospective studies (26-29) and one was a retrospective study (15). In total, 1,700 patients were included (Table III).

Hypertension as an adverse event of antiangiogenic therapy. Two double-blind, randomized, placebo-controlled, phase III trials for ramucirumab $(27,28)$ and the phase II and III studies for apatinib $(26,29)$ showed that ramucirumab and apatinib increased the risk of $\geq \mathrm{G} 3$ hypertension in patients with $\mathrm{GC}$ or GEJ carcinoma. The incidence of hypertension in the TKI treatment group $(36.80 \%)$ was higher compared with the group treated with monoclonal antibodies (22.78\%). However, the incidence of severe hypertension in the monoclonal antibody treatment group (11.37\%) was higher compared with the TKI-treated group (6.32\%). Of note, the incidence of severe hypertension was higher in the dose of $425 \mathrm{mg}$ twice daily compared with the dose of $850 \mathrm{mg}$ once-daily regimen (26), but this comparison lacked statistical significance.

Hypertension as a biomarker of effective antiangiogenic therapy. A retrospective cohort study of 269 patients demonstrated that the presence of hypertension within the first four weeks of antiangiogenic therapy was associated with prolonged median overall survival (15), suggesting that hypertension is an early prognostic marker. However, further studies are required to support this conclusion.

\section{Relationship between antiangiogenic therapy and hy- pertension in lung cancer}

Bevacizumab is the most widely used antiangiogenic drug for lung cancer treatment. Twelve studies have reported the association between hypertension and approved antiangiogenic drugs, including fruquintinib, crediranib anlotinib and bevacizumab. 
Table I. Definitions of hypertension grades for adults according to the National Cancer Institute's common terminology criteria for adverse events version 5.0.

Grade Definition Treatment

$1 \quad$ Systolic BP 120-139 mm Hg or diastolic BP 80-89 mmHg

2 Systolic BP 140-159 mm Hg or diastolic BP 90-99 mm Hg if previously within normal level;

Recurrent or persistent ( $\geq 24 \mathrm{~h})$;

Symptomatic increase by $>20 \mathrm{~mm} \mathrm{Hg}$ (diastolic) or to $>140 / 90 \mathrm{~mm} \mathrm{Hg}$

3 Systolic $\mathrm{BP} \geq 160 \mathrm{mmHg}$ or diastolic $\mathrm{BP} \geq 100 \mathrm{mmHg}$

4 Life-threatening consequences (for example, malignant hypertension, transient or permanent neurologic deficit, hypertensive crisis)

5 Death

\section{NR}

Monotherapy or change in baseline medical intervention

NR

Urgent intervention

BP, blood pressure; NR, not reported.

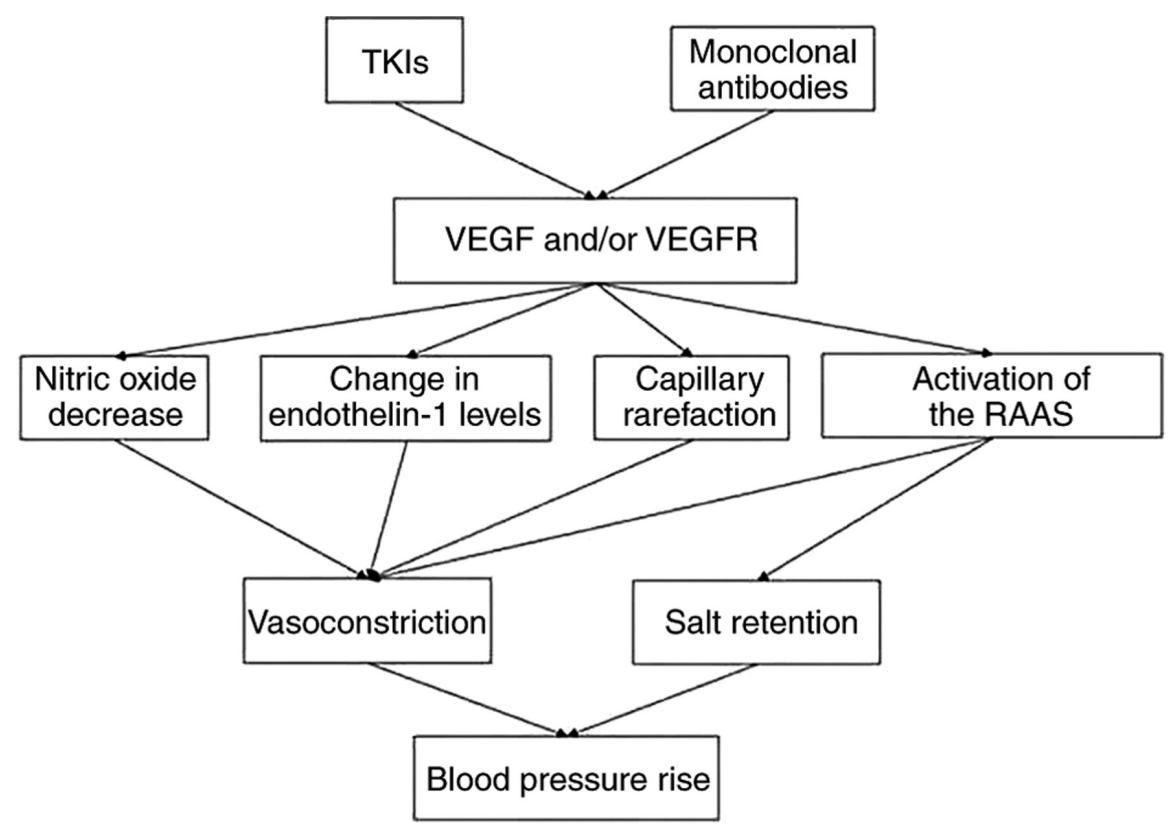

Figure 1. Possible mechanism of hypertension induced by antiangiogenic drugs. Monoclonal antibodies block the binding of VEGF to VEGFR, then prevent activation of intracellular signal transduction. Small-molecule TKIs act on the intracellular domain of the VEGFR, where they inhibit the initial phosphorylation step after the ligand-receptor interaction. Blocking the effect of VEGF/VEGFR can inhibit the production of nitric oxide, change the levels of endothelin-1 and reduce the production of capillaries. These effects induce vasoconstriction and inhibit tumor growth and metastasis, but at the same time, vasoconstriction also promotes the increase of blood pressure. In addition, several studies have shown that blocking the VEGF/VEGFR pathway can activate the RAAS, promote water and sodium retention, and raise blood pressure. VEGF, vascular endothelial growth factor; VEGFR, vascular endothelial growth factor receptor; TKIs, tyrosine kinase inhibitors; RAAS, renin-angiotensin-aldosterone system.

There are seven prospective studies (30-36), two retrospective studies $(14,37)$ and three meta-analyses (38-40). A total of 1,1291 patients were included (Table IV).

Hypertension as an adverse event of antiangiogenic therapy. Bevacizumab increased the risk of severe hypertension in the high-dose group $(15 \mathrm{mg} / \mathrm{kg})(32,39)$ and amongst female patients (41). There was no significant difference between different races (30), pathological types (38) and age (42). Discontinuation of medication due to hypertension was extremely rare $(30,39)$. Based on these data, it was found in the present study that the incidence of hypertension in the
TKI treatment group (59.72\%) was higher compared with the group treated with the monoclonal antibodies $(28.61 \%)$. The incidence of hypertension was the highest in the anlotinib group $(67.3 \%)$. A total of $13.6 \%$ patients developed severe hypertension during therapy. Notably, $23 \%$ of patients developed severe hypertension when receiving bevacizumab plus erlotinib (34).

Hypertension as a biomarker of antiangiogenic therapy. Two studies of bevacizumab $(14,37)$ and one study of cediranib (36) suggested that the early development of hypertension was associated with clinical benefit. 


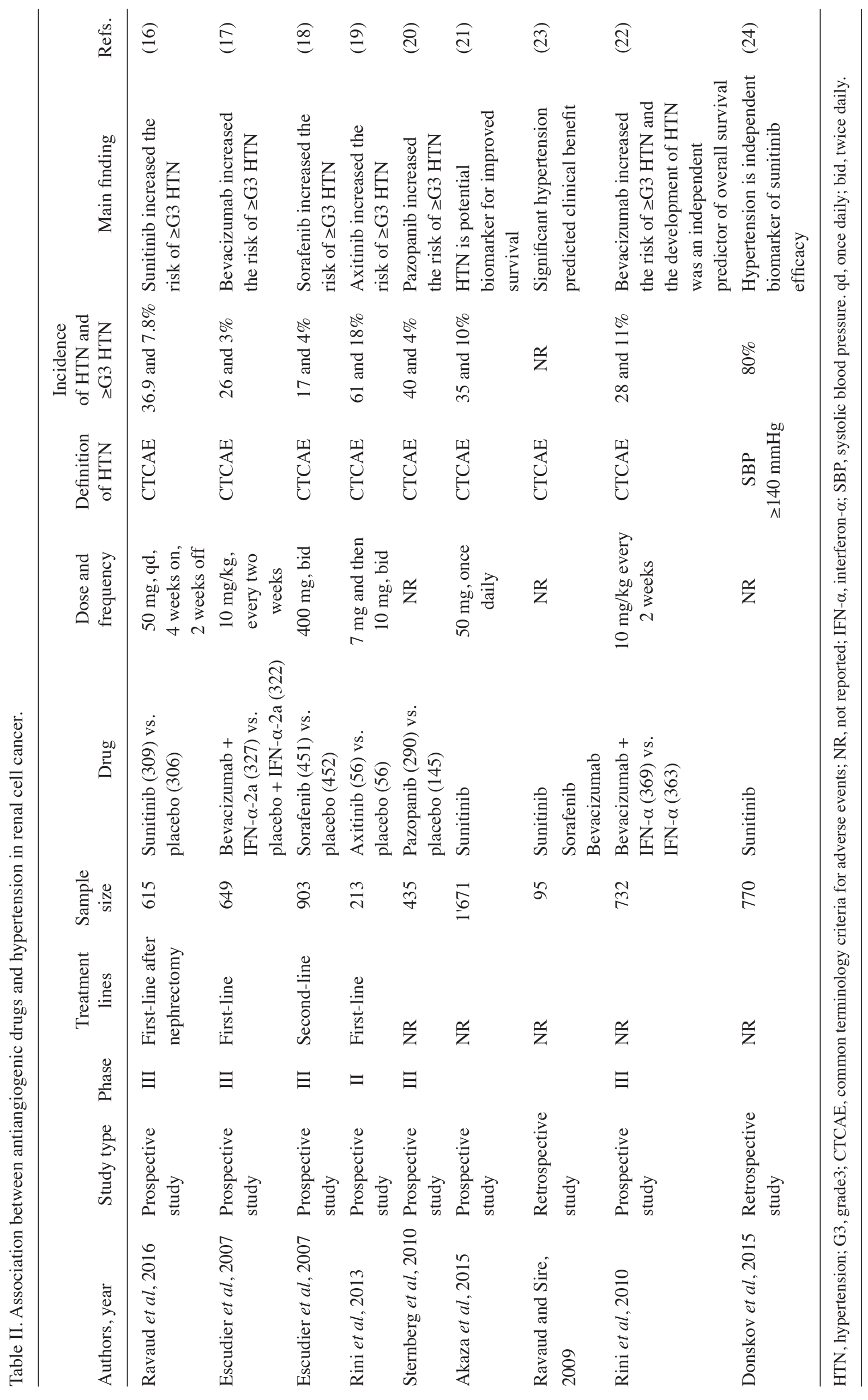




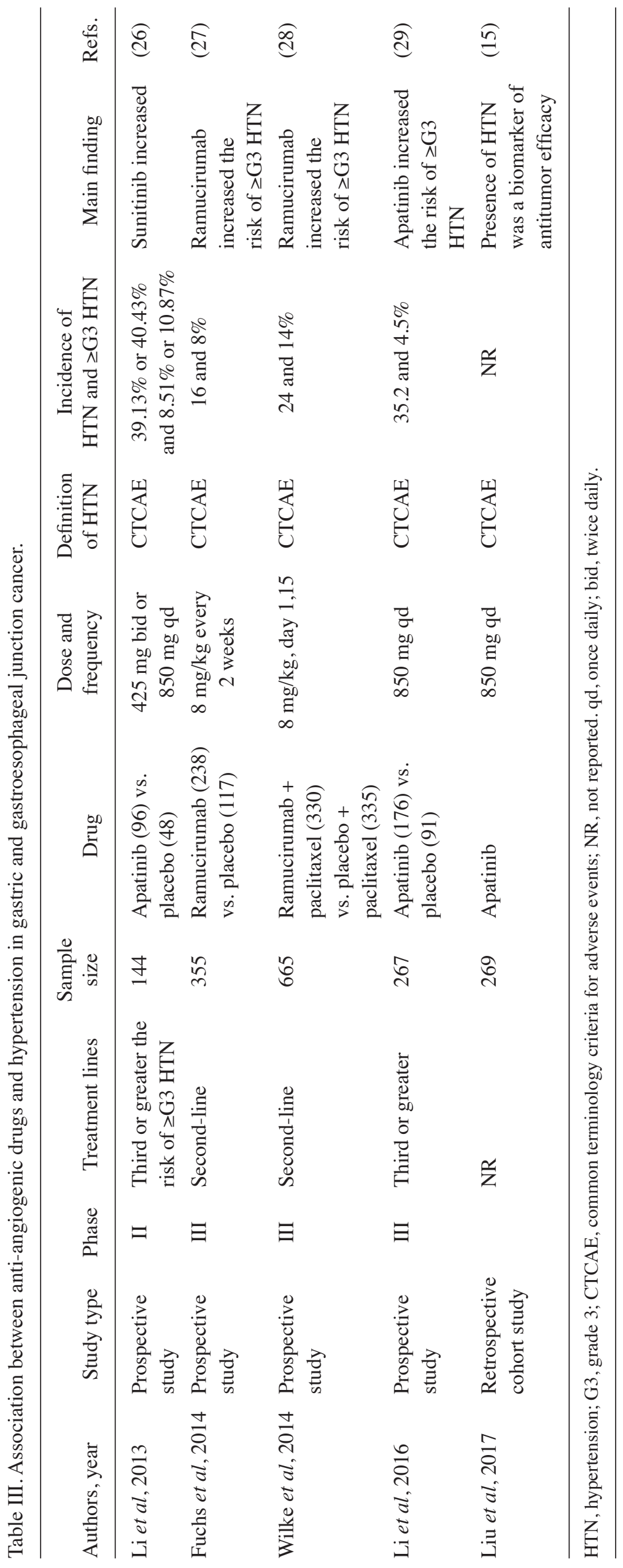




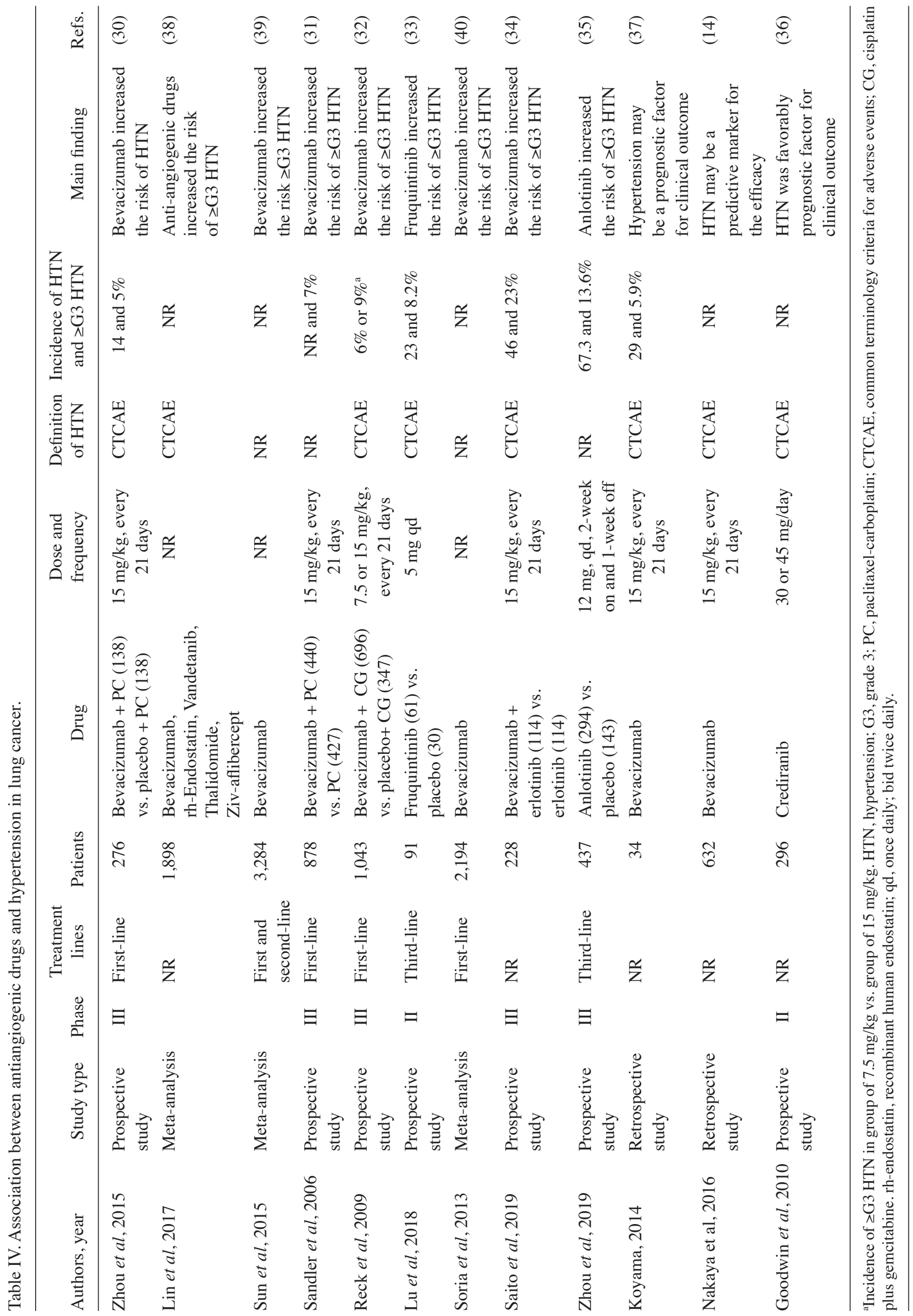




\section{Relationship between antiangiogenic therapy and hy- pertension in colorectal cancer}

Antiangiogenic therapy improved the overall survival of patients with colorectal cancer, but its benefit is offset partially by adverse events, such as hypertension. Thirteen studies have reported significant associations between hypertension and antiangiogenic drugs, including bevacizumab, ramucirumab and fruquintinib. There are six prospective studies (43-48), three retrospective studies $(14,49,50)$, three meta-analyses (51-53) and one cohort study (54), including a total of 22,639 patients (Table V).

Hypertension as an adverse event of antiangiogenic therapy. A meta-analysis of 10,180 participants treated with bevacizumab (51), two randomized controlled studies for regorafenib (47) and a phase III controlled trial for ramucirumab (55) showed that these drugs increased the incidence of severe hypertension in patients with colorectal cancer. Hypertension caused by antiangiogenic drugs was associated with age $(43,56,57)$ and regimen $(58)$, but no association was observed with VEGF-D levels (55), race (59), cancer stage (45) or treatment line $(47,48)$. Based on the aforementioned studies, the incidence of severe hypertension in the monoclonal antibodies group (13.11\%) was higher than the TKI group (9.14\%). Notably, bevacizumab was less likely to induce severe hypertension in elderly patients (age, $\geq 75$ years) $(43,56,57)$.

Hypertension as a biomarker of antiangiogenic therapy. Three retrospective studies $(14,49,50)$ and a cohort study (54) of bevacizumab showed that early developing hypertension may be a predictive marker for the efficacy of bevacizumab.

Examples of trials that did not increase the risk of hypertension. Other studies have reported that bevacizumab did not significantly increase the risk of severe hypertension in patients receiving the drug $(60,61)$ and patients who were aged $\geq 70$ (57). However, the former conclusion may have selection bias, because amongst the patients who have previously received bevacizumab treatment, only patients who have not developed severe hypertension receive bevacizumab treatment again.

\section{Relationship between antiangiogenic therapy and hy- pertension in hepatocellular carcinoma}

Antiangiogenic drugs have an important role in the treatment of hepatocellular carcinoma (62). Five studies have reported the association between hypertension and antiangiogenic drugs, including cabozantinib, regorafenib, sorafenib and ramucirumab, in hepatocellular carcinoma. There are four prospective studies (63-66) and one retrospective study (67). A total of 2,272 patients were included (Table VI).

Hypertension as an adverse event of antiangiogenic therapy. Four phase III, randomized, double-blind, placebo-controlled trials of antiangiogenic drugs, including cabozantinib, regorafenib and ramucirumab, reported an increasing risk of severe hypertension in the drug-treated group, with an incidence of $13-16 \%$ (63-66). Based on the given data, it was found in the present study that the incidence of severe hypertension in the TKI-treated group (14.51\%) was moderately greater compared with the monoclonal antibodies-treated group (13.66\%).

Hypertension as a biomarker of antiangiogenic therapy. One retrospective study of 38 patients suggested that hypertension within two weeks of therapy initiation may be a positive predictor of the anticancer efficacy of sorafenib in patients with hepatocellular carcinoma (67).

Examples of trials that didnot increase the risk of hypertension. Three multicenter, phase III, double-blind, placebo-controlled trials showed that sorafenib did not significantly increase the risk of severe hypertension in patients with advanced hepatocellular carcinoma (68-70). This may be a unique manifestation of sorafenib in hepatocellular carcinoma.

\section{Relationship between antiangiogenic therapy and hyper- tension in breast cancer}

Antiangiogenic agents have been used extensively for the treatment of breast cancer, but high rates of treatment-induced hypertension have been reported (71). Six studies have reported the association between hypertension and antiangiogenic drugs including, bevacizumab and axitinib, in breast cancer. There are four prospective studies (72-75), one retrospective study (76) and one meta-analysis (77), with a total of 7,414 patients included (Table VII).

Hypertension as an adverse event of antiangiogenic therapy. A meta-analysis of five clinical trials reported that bevacizumab increased the risk of severe hypertension (77). Severe hypertension was more frequent in the high-dose group (73) and in some specific genotypes (76). In specific, Schneider et al (76) demonstrated that those with VEGF-1498TT and VEGF-634CC genotypes were largely protected from severe hypertension. There was no clear correlation between severe hypertension and baseline blood pressure (78). Based on the given data, it was found in the present study that the incidence of severe hypertension in the TKI-treated group (17.5\%) was higher compared with the monoclonal antibodies-treated group (6.6\%).

Hypertension as a biomarker of antiangiogenic therapy. Biomarker analysis of the Eastern Cooperative Oncology Group clinical trial E2100 demonstrated that patients with severe hypertension had a superior median overall survival, and that the VEGF-2578 AA genotype was associated with improved outcome (76). Another study of apatinib showed that the predictive effect of hypertension was not related to the grade of hypertension (75).

\section{Discussion}

The present brief review examined the association between hypertension and antiangiogenic therapy in different types of cancer. There are several key findings reported in the present review. First, the use of antiangiogenic drugs was associated with an increased risk of hypertension in most types of solid cancer. Based on the analyzed data, the incidence of hypertension $(33.39 \%)$ was the highest in lung cancer. In addition, the 


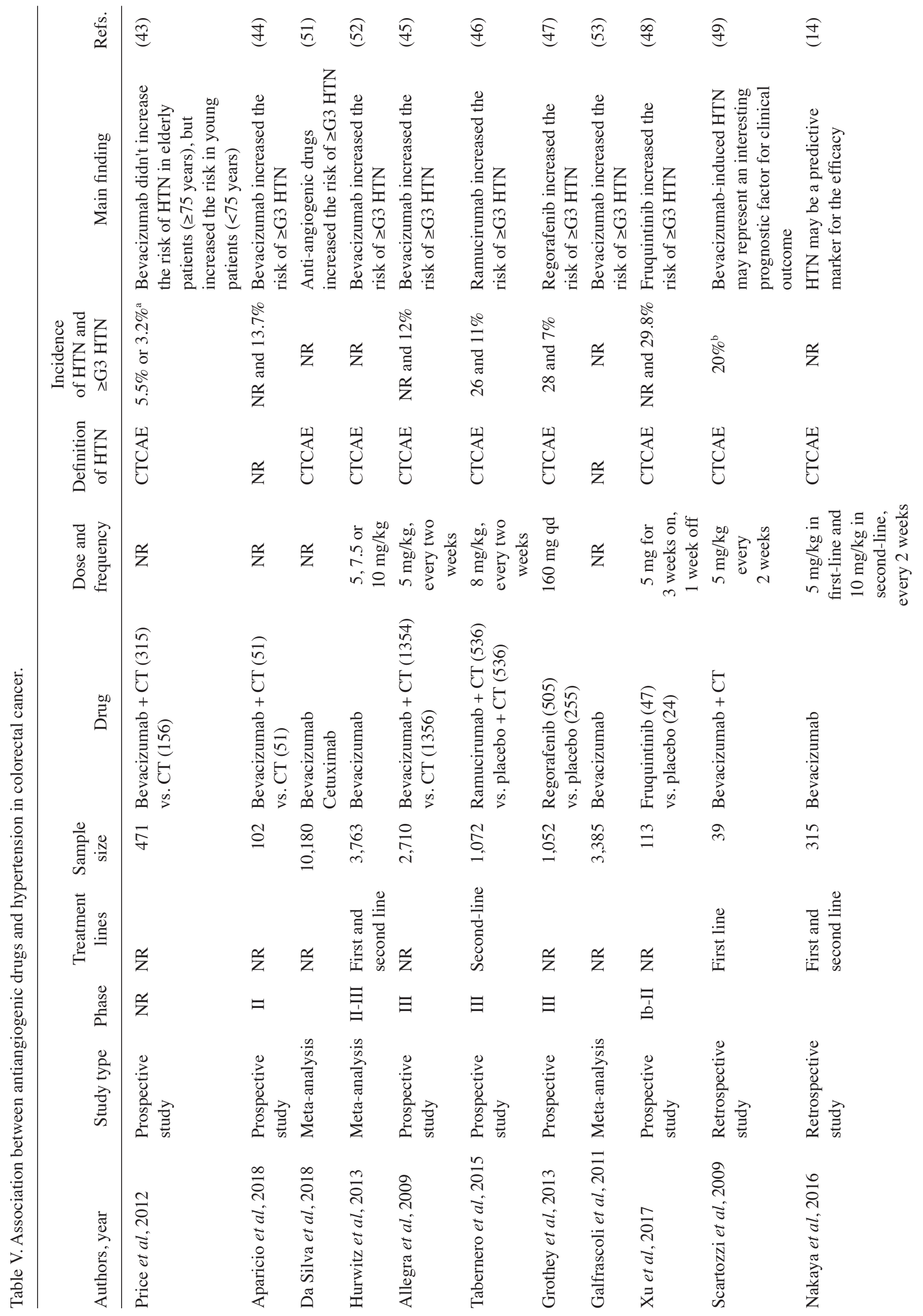



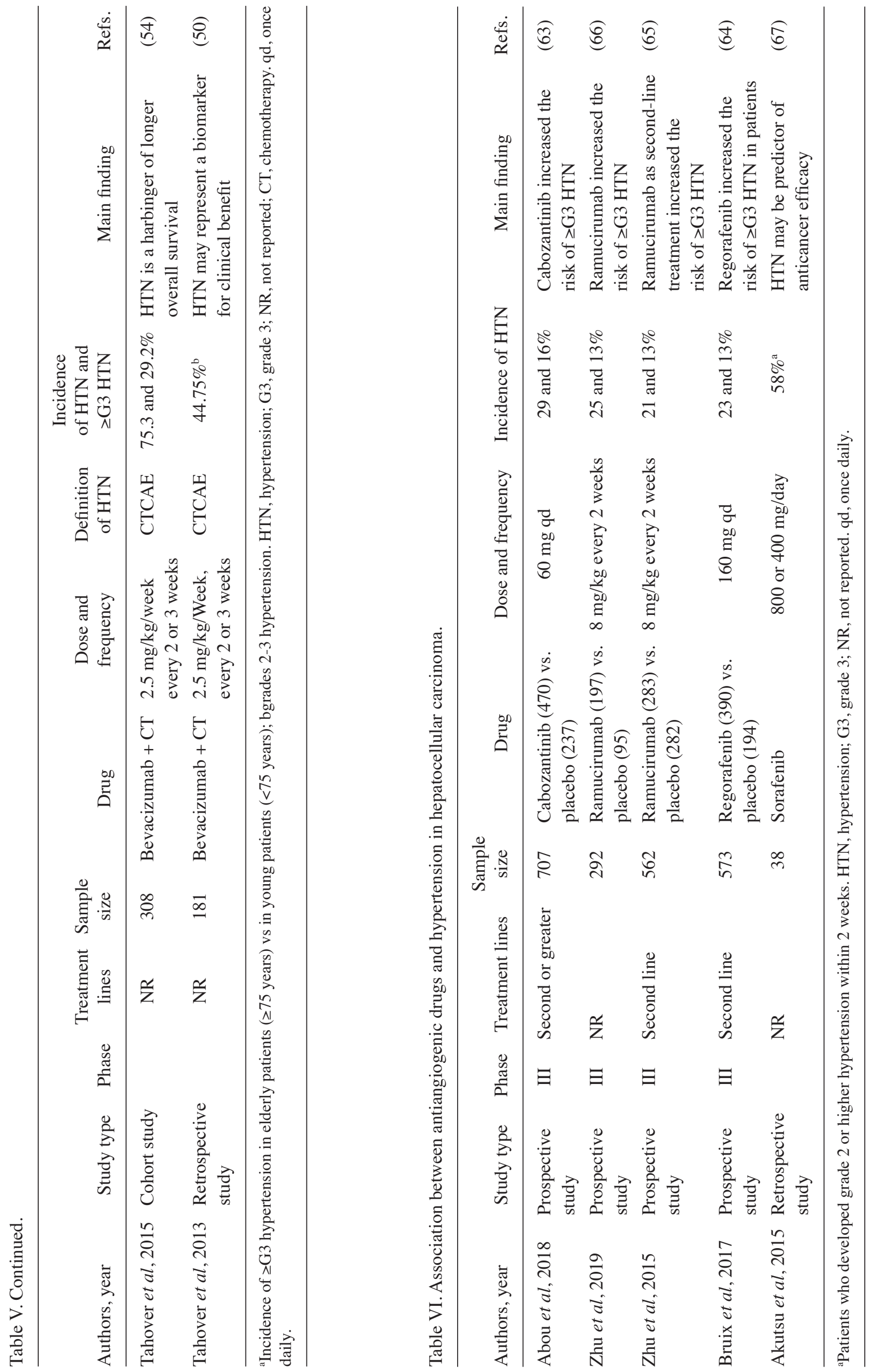
incidence of severe hypertension was the highest in hepatocellular carcinoma (13.48\%) and the lowest in breast cancer (7.1\%). Second, there was no significant difference in the incidence of hypertension between monoclonal antibodies and small molecule TKI treatments. Of note, the use of several novel TKIs has been associated with a higher incidence of severe hypertension, such as axitinib in renal cell cancer (18\%) (19), fruquintinib in colorectal cancer (29.8\%) (48), apatinib in breast cancer $(17.5 \%)(75)$, and combination of bevacizumab with erlotinib in lung cancer (23\%) (34). However, this effect was not observed in the combined antiangiogenic immunotherapy arm (79). In addition, hypertension as an adverse event was more common in patients receiving high doses (41), however, the effect of frequency of administration on the occurrence of hypertension remains unclear. Third, hypertension was more likely to occur in patients younger than 75 years old $(43,56,57)$, those who have not previously used bevacizumab $(60,61)$, and female patients (41). Fourth, the effect of baseline blood pressure levels on the development of hypertension is controversial. Pivot et al (78) reported that there was no clear correlation between baseline hypertension and its development during study treatment. By contrast, Yang et al (80) found that a history of hypertension was an independent risk factor for predicting hypertension during the treatment period. Fifth, discontinuation or death caused by hypertension was rare. Nevertheless, hypertension was a risk factor for acute and chronic cardiovascular diseases and ischemic stroke, with the grade of hypertension associated with mortality $(77,81)$. Finally, early development of significant hypertension may be a biomarker associated with greater efficacy of antiangiogenic therapy and improved survival $(14,49,50)$.

Large doses of antiangiogenic agents are generally associated with greater inhibitory effects on VEGF. We speculate that higher sensitivity to angiogenesis inhibitors may be an explanation, due to different levels of VEGF expression. Patients with RCC have increased levels of VEGF and VEGFR expression (82), which is accompanied by higher rates of hypertension development, compared with hepatocellular carcinoma patients treated with sorafenib (83). Frey et al (84) have shown that bevacizumab-induced hypertension is related to genetic variation in WNK lysine deficient protein kinase 1, kallikrein B1 and G protein-coupled receptor kinase 4 . The performance of sunitinib in patients with non-small cell lung cancer (85), bevacizumab in Chinese patients with locally progressed GC (86), as well as sorafenib (87) and sunitinib (88) in patients with breast cancer, confirms our hypothesis: These drugs did not increase the risk of serious hypertension, but at the same time, they did not improve survival.

As an adverse event, hypertension caused by antiangiogenic drugs should be monitored regularly by physicians. There is a role for home or ambulatory blood pressure monitoring, which can increase the sensitivity of diagnosing hypertension (89). Nevertheless, blood pressure monitoring in the clinic is recommended for the first cycle of therapy (90). When blood pressure remains $<140 / 90 \mathrm{mmHg}$, lifestyle intervention is recommended, which includes lower salt intake, reduced alcohol consumption, normalization of the body mass index, no cigarette smoking and increased physical activity (91). Antihypertensive therapy should be initiated when blood pressure is $>140 / 90 \mathrm{mmHg}$ or $20 \mathrm{mmHg}$ greater than the baseline blood pressure (90). The 
association between antihypertensive drugs and cancer is a matter of large debate in the last several years. At present, renin inhibitors, including ACEIs and angiotensin receptor blockers, are the first-line agents preferred for antiangiogenetic therapy, since they can improve remodeling by reducing left ventricular afterload and by direct inhibition of angiotensin II type 1 receptor-mediated hypertrophy and fibrosis (13). After the end of antiangiogenic drug treatment, blood pressure should be regularly monitored, and antihypertensive treatment should be discontinued if it normalizes.

On the other hand, the presence of hypertension has been reported as a positive prognostic biomarker of improved survival in patients receiving antiangiogenic therapy. However, the underlying mechanisms, the timing and value of blood pressure that best predicts survival needs to be elucidated. Previous studies have shown that significant hypertension $[\geq \mathrm{G} 2(22,23)$ or $\geq \mathrm{G} 3$ (76)] and early occurrence of hypertension [in the first two (67), four (15) or six weeks of treatment initiation (21)] may be associated with improved survival. However, it is unclear whether patients who do not develop significant hypertension in the early stage need alterations in the medication regimen (15).

\section{Conclusion}

In conclusion, the use of antiangiogenic drugs is associated with an increased risk of hypertension in most types of solid cancer. Early development of significant hypertension may be a potential biomarker of improved survival. Prospective studies are needed to support these findings.

\section{Acknowledgements}

The authors would like to thank Dr Sharen Lee (Cardiovascular Analytics Group, Laboratory of Cardiovascular Physiology, Hong Kong) for his contribution to the revision of the manuscript and data interpretation.

\section{Funding}

No funding was received.

\section{Availability of data and materials}

Not applicable.

\section{Authors' contributions}

GT, PS and LZ designed and arranged the manuscript. MD and RW wrote the article. DZ, ZZ and JZ found and analyzed the references in Medline, and participated in writing the article. All authors read and approved the final manuscript.

\section{Ethics approval and consent to participate}

Not applicable.

\section{Patient consent for publication}

Not applicable.

\section{Competing interests}

The authors declare that they have no competing interests.

\section{References}

1. Hanahan D and Weinberg RA: Hallmarks of cancer: The next generation. Cell 144: 646-674, 2011.

2. Vasudev NS and Reynolds AR: Anti-angiogenic therapy for cancer: Current progress, unresolved questions and future directions. Angiogenesis 17: 471-494, 2014

3. Brinda BJ, Viganego F, Vo T, Dolan D and Fradley MG: Anti-VEGF-induced hypertension: A review of pathophysiology and treatment options. Curr Treat Options Cardiovasc Med 18: 33, 2016.

4. Eskens FA and Verweij J: The clinical toxicity profile of vascular endothelial growth factor (VEGF) and vascular endothelial growth factor receptor (VEGFR) targeting angiogenesis inhibitors; A review. Eur J Cancer 42: 3127-3139, 2006.

5. Abi Aad S, Pierce M, Barmaimon G, Farhat FS, Benjo A and Mouhayar E: Hypertension induced by chemotherapeutic and immunosuppresive agents: A new challenge. Crit Rev Oncol Hematol 93: 28-35, 2015.

6. Neagoe PE, Lemieux C and Sirois MG: Vascular endothelial growth factor (VEGF)-A165-induced prostacyclin synthesis requires the activation of VEGF receptor-1 and -2 heterodimer. J Biol Chem 280: 9904-9912, 2005.

7. Neves KB, Rios FJ, Jones R, Evans TRJ, Montezano AC and Touyz RM: Microparticles from vascular endothelial growth factor pathway inhibitor-treated cancer patients mediate endothelial cell injury. Cardiovasc Res 115: 978-988, 2019.

8. Hasinoff BB and Patel D: Mechanisms of myocyte cytotoxicity induced by the multikinase inhibitor sorafenib. Cardiovasc Toxicol 10: 1-8, 2010.

9. Semeniuk-Wojtaś A, Lubas A, Stec R, Szczylik C and Niemczyk S: Influence of tyrosine kinase inhibitors on hypertension and nephrotoxicity in metastatic renal cell cancer patients. Int J Mol Sci 17: 2073, 2016.

10. U.S. Department of Health and Human Services: Common Terminology Criteria For Adverse Events (CTCAE). Version 5.0, 2017. https://ctep.cancer.gov/protocoldevelopment/electronic applications/docs/ctcae_v5_quick_reference_5x7.pdf. Accessed, November 27, 2017.

11. Bæk Møller N, Budolfsen C, Grimm D, Krüger M, Infanger M, Wehland M and Magnusson N: Drug-induced hypertension caused by multikinase inhibitors (sorafenib, sunitinib, lenvatinib and axitinib) in renal cell carcinoma treatment. Int J Mol Sci 20: 4712, 2019.

12. Tadic M, Cuspidi C, Belyavskiy E and Grassi G: Intriguing relationship between antihypertensive therapy and cancer. Pharmacol Res 141: 501-511, 2019.

13. Pinter M, Kwanten WJ and Jain RK: Renin-angiotensin system inhibitors to mitigate cancer treatment-related adverse events. Clin Cancer Res 24: 3803-3812, 2018.

14. Nakaya A, Kurata T, Yokoi T, Iwamoto S, Torii Y, Katashiba Y, Ogata M, Hamada M, Kon M and Nomura S: Retrospective analysis of bevacizumab-induced hypertension and clinical outcome in patients with colorectal cancer and lung cancer. Cancer Med 5: 1381-1387, 2016.

15. Liu X, Qin S, Wang Z, Xu J, Xiong J, Bai Y, Wang Z, Yang Y, Sun G, Wang L, et al: Early presence of anti-angiogenesis-related adverse events as a potential biomarker of antitumor efficacy in metastatic gastric cancer patients treated with apatinib: A cohort study. J Hematol Oncol 10: 153, 2017.

16. Ravaud A, Motzer RJ, Pandha HS, George DJ, Pantuck AJ, Patel A, Chang YH, Escudier B, Donskov F, Magheli A, et al: Adjuvant sunitinib in high-risk renal-cell carcinoma after nephrectomy. N Engl J Med 375: 2246-2254, 2016.

17. Escudier B, Pluzanska A, Koralewski P, Ravaud A, Bracarda S, Szczylik C, Chevreau C, Filipek M, Melichar B, Bajetta E, et al: Bevacizumab plus interferon alfa-2a for treatment of metastatic renal cell carcinoma: A randomised, double-blind phase III trial. Lancet 370: 2103-2111, 2007.

18. Escudier B, Eisen T, Stadler WM, Szczylik C, Oudard S, Siebels M, Negrier S, Chevreau C, Solska E, Desai AA, et al: Sorafenib in advanced clear-cell renal-cell carcinoma. N Engl J Med 356: 125-134, 2007. 
19. Rini BI, Melichar B, Ueda T, Grünwald V, Fishman MN, Arranz JA, Bair AH, Pithavala YK, Andrews GI, Pavlov D, et al: Axitinib with or without dose titration for first-line metastatic renal-cell carcinoma: A randomised double-blind phase 2 trial Lancet Oncol 14: 1233-1242, 2013.

20. Sternberg CN, Davis ID, Mardiak J, Szczylik C, Lee E, Wagstaff J, Barrios CH, Salman P, Gladkov OA, Kavina A, et al: Pazopanib in locally advanced or metastatic renal cell carcinoma: Results of a randomized phase III trial. J Clin Oncol 28: 1061-1068, 2010

21. Akaza H, Naito S, Ueno N, Aoki K, Houzawa H, Pitman Lowenthal S and Lee SY: Real-world use of sunitinib in Japanese patients with advanced renal cell carcinoma: Efficacy, safety and biomarker analyses in 1689 consecutive patients. Jpn J Clin Oncol 45: 576-583, 2015.

22. Rini BI, Halabi S, Rosenberg JE, Stadler WM, Vaena DA, Archer L, Atkins JN, Picus J, Czaykowski P, Dutcher J and Small EJ: Phase III trial of bevacizumab plus interferon alfa versus interferon alfa monotherapy in patients with metastatic renal cell carcinoma: Final results of CALGB 90206. J Clin Oncol 28: 2137-2143, 2010

23. Ravaud A and Sire M: Arterial hypertension and clinical benefit of sunitinib, sorafenib and bevacizumab in first and second-line treatment of metastatic renal cell cancer. Ann Oncol 20: 966-967, 2009.

24. Donskov F, Michaelson MD, Puzanov I, Davis MP, Bjarnason GA, Motzer RJ, Goldstein D, Lin X, Cohen DP, Wiltshire R and Rini BI: Sunitinib-associated hypertension and neutropenia as efficacy biomarkers in metastatic renal cell carcinoma patients. Br J Cancer 113: 1571-1580, 2015.

25. Goldstein D, Rosenberg JE, Figlin RA, Townsend RR, McCann L, Carpenter $\mathrm{C}$ and Pandite L: Is change in blood pressure a biomarker of pazopanib and sunitinib efficacy in advanced/metastatic renal cell carcinoma? Eur J Cancer 53: 96-104, 2016.

26. Li J, Qin S, Xu J, Guo W, Xiong J, Bai Y, Sun G, Yang Y, Wang L, Xu N, et al: Apatinib for chemotherapy-refractory advanced metastatic gastric cancer: Results from a randomized, placebo-controlled, parallel-arm, phase II trial. J Clin Oncol 31: 3219-3225, 2013.

27. Fuchs CS, Tomasek J, Yong CJ, Dumitru F, Passalacqua R, Goswami C, Safran H, Dos Santos LV, Aprile G, Ferry DR, et al: Ramucirumab monotherapy for previously treated advanced gastric or gastro-oesophageal junction adenocarcinoma (REGARD): An international, randomised, multicentre, placebo-controlled, phase 3 trial. Lancet 383: 31-39, 2014.

28. Wilke H, Muro K, Van Cutsem E, Oh SC, Bodoky G, Shimada Y, Hironaka S, Sugimoto N, Lipatov O, Kim TY, et al: Ramucirumab plus paclitaxel versus placebo plus paclitaxel in patients with previously treated advanced gastric or gastro-oesophageal junction adenocarcinoma (RAINBOW): A double-blind, randomised phase 3 trial. Lancet Oncol 15: 1224-1235, 2014.

29. Li J, Qin S, Xu J, Xiong J, Wu C, Bai Y, Liu W, Tong J, Liu Y, $\mathrm{Xu}$ R, et al: Randomized, double-blind, placebo-controlled phase III trial of apatinib in patients with chemotherapy-refractory advanced or metastatic adenocarcinoma of the stomach or gastroesophageal junction. J Clin Oncol 34: 1448-1454, 2016

30. Zhou C, Wu YL, Chen G, Liu X, Zhu Y, Lu S, Feng J, He J, Han B, Wang J, et al: BEYOND: A randomized, double-blind, placebo-controlled, multicenter, phase III study of first-line carboplatin/paclitaxel plus bevacizumab or placebo in Chinese patients with advanced or recurrent nonsquamous non-small-cell lung cancer. J Clin Oncol 33: 2197-2204, 2015.

31. Sandler A, Gray R, Perry MC, Brahmer J, Schiller JH, Dowlati A, Lilenbaum R and Johnson DH: Paclitaxel-carboplatin alone or with bevacizumab for non-small-cell lung cancer. N Engl J Med 355: 2542-2550, 2006.

32. Reck M, von Pawel J, Zatloukal P, Ramlau R, Gorbounova V, Hirsh V, Leighl N, Mezger J, Archer V, Moore N and Manegold C: Phase III trial of cisplatin plus gemcitabine with either placebo or bevacizumab as first-line therapy for nonsquamous non-small-cell lung cancer: AVAil. J Clin Oncol 27: 1227-1234, 2009.

33. Lu S, Chang J, Liu X, Shi J, Lu Y, Li W, Yang JJ, Zhou J, Wang J, An T, et al: Randomized, double-blind, placebo-controlled, multicenter phase II study of fruquintinib after two prior chemotherapy regimens in chinese patients with advanced nonsquamous nonsmall-cell lung cancer. J Clin Oncol 36: 1207-1217, 2018

34. Saito H,FukuharaT,Furuya N, Watanabe K, Sugawara S, IwasawaS, Tsunezuka Y, Yamaguchi O, Okada M, Yoshimori K, et al: Erlotinib plus bevacizumab versus erlotinib alone in patients with EGFR-positive advanced non-squamous non-small-cell lung cancer (NEJ026): Interim analysis of an open-label, randomised, multicentre, phase 3 trial. Lancet Oncol 20: 625-635, 2019.
35. Zhou M, Chen X, Zhang H, Xia L, Tong X, Zou L, Hao R, Pan J, Zhao X, Chen D, et al: China national medical products administration approval summary: Anlotinib for the treatment of advanced non-small cell lung cancer after two lines of chemotherapy. Cancer Commun (Lond) 39: 36, 2019.

36. Goodwin R, Ding K, Seymour L, LeMaitre A, Arnold A, Shepherd FA, Dediu M, Ciuleanu T, Fenton D, Zukin M, et al: Treatment-emergent hypertension and outcomes in patients with advanced non-small-cell lung cancer receiving chemotherapy with or without the vascular endothelial growth factor receptor inhibitor cediranib: NCIC clinical trials group study BR24. Ann Oncol 21: 2220-2226, 2010.

37. Koyama N: Adverse cardiovascular events predict survival benefit in non-small lung cancer patients treated with bevacizumab. Cancer Biomark 14: 259-265, 2014.

38. Lin H, Li L, Luo S, Zhou S, Shen R, Yang H, Chen H and Xie X: Efficacy and safety of angiogenesis inhibitors in small-cell lung cancer. Oncology 8: 1141-1155, 2017.

39. Sun L, Ma JT, Zhang SL, Zou HW and Han CB: Efficacy and safety of chemotherapy or tyrosine kinase inhibitors combined with bevacizumab versus chemotherapy or tyrosine kinase inhibitors alone in the treatment of non-small cell lung cancer: A systematic review and meta-analysis. Med Oncol 32: 473, 2015.

40. Soria JC, Mauguen A, Reck M, Sandler AB, Saijo N, Johnson DH, Burcoveanu D, Fukuoka M, Besse B and Pignon JP; meta-analysis of bevacizumab in advanced NSCLC collaborative group: Systematic review and meta-analysis of randomised, phase II/III trials adding bevacizumab to platinum-based chemotherapy as first-line treatment in patients with advanced non-small-cell lung cancer. Ann Oncol 24: 20-30, 2013.

41. Brahmer JR, Dahlberg SE, Gray RJ, Schiller JH, Perry MC, Sandler A and Johnson DH: Sex differences in outcome with bevacizumab therapy: Analysis of patients with advanced-stage non-small cell lung cancer treated with or without bevacizumab in combination with paclitaxel and carboplatin in the Eastern cooperative oncology group trial 4599. J Thorac Oncol 6: 103-108, 2011.

42. Leighl NB, Zatloukal P, Mezger J, Ramlau R, Moore N, Reck M and Manegold C: Efficacy and safety of bevacizumab-based therapy in elderly patients with advanced or recurrent nonsquamous non-small cell lung cancer in the phase III BO17704 study (AVAiL). J Thorac Oncol 5: 1970-1976, 2010.

43. Price TJ, Zannino D, Wilson K, Simes RJ, Cassidy J, Van Hazel GA, Robinson BA, Broad A, Ganju V, Ackland SP and Tebbutt NC: Bevacizumab is equally effective and no more toxic in elderly patients with advanced colorectal cancer: A subgroup analysis from the AGITG MAX trial: An international randomised controlled trial of capecitabine, bevacizumab and mitomycin C. Ann Oncol 23: 1531-1536, 2012.

44. Aparicio T, Bouché O, Taieb J, Maillard E, Kirscher S, Etienne PL, Faroux R, Khemissa Akouz F, El Hajbi F, Locher C, et al: Bevacizumab+chemotherapy versus chemotherapy alone in elderly patients with untreated metastatic colorectal cancer: A randomized phase II trial-PRODIGE 20 study results. Ann Oncol 29: 133-138, 2018.

45. Allegra CJ, Yothers G, O'Connell MJ, Sharif S, Colangelo LH, Lopa SH, Petrelli NJ, Goldberg RM, Atkins JN, Seay TE, et al: Initial safety report of NSABP C-08: A randomized phase III study of modified FOLFOX6 with or without bevacizumab for the adjuvant treatment of patients with stage II or III colon cancer. J Clin Oncol 27: 3385-3390, 2009.

46. Tabernero J, Yoshino T, Cohn AL, Obermannova R, Bodoky G, Garcia-Carbonero R, Ciuleanu TE, Portnoy DC, Van Cutsem E, Grothey A, et al: Ramucirumab versus placebo in combination with second-line FOLFIRI in patients with metastatic colorectal carcinoma that progressed during or after first-line therapy with bevacizumab, oxaliplatin, and a fluoropyrimidine (RAISE): A randomised, double-blind, multicentre, phase 3 study. Lancet Oncol 16: 499-508, 2015.

47. Grothey A, Cutsem EV, Sobrero A, Siena S, Falcone A Ychou M, Humblet Y, Bouché O, Mineur L, Barone C, et al: Regorafenib monotherapy for previously treated metastatic colorectal cancer (CORRECT): An international, multicentre, randomised, placebo-controlled, phase 3 trial. Lancet 381: 303-312, 2013.

48. Xu RH, Li J, Bai Y, Xu J, Liu T, Shen L, Wang L, Pan H, Cao J, Zhang D, et al: Safety and efficacy of fruquintinib in patients with previously treated metastatic colorectal cancer: A phase Ib study and a randomized double-blind phase II study. J Hematol Oncol 10: 22, 2017. 
49. Scartozzi M, Galizia E, Chiorrini S, Giampieri R, Berardi R, Pierantoni $C$ and Cascinu S: Arterial hypertension correlates with clinical outcome in colorectal cancer patients treated with first-line bevacizumab. Ann Oncol 20: 227-230, 2009.

50. Tahover E, Uziely B, Salah A, Temper M, Peretz T and Hubert A: Hypertension as a predictive biomarker in bevacizumab treatment for colorectal cancer patients. Med Oncol 30: 327, 2013.

51. da Silva WC, de Araujo VE, Lima EMEA, Dos Santos JBR, Silva MRRD, Almeida PHRF, de Assis Acurcio F, Godman B, Kurdi A, Cherchiglia ML and Andrade EIG: Comparative effectiveness and safety of monoclonal antibodies (bevacizumab, cetuximab, and panitumumab) in combination with chemotherapy for metastatic colorectal cancer: A systematic review and meta-analysis. BioDrugs 32: 585-606, 2018.

52. Hurwitz HI, Tebbutt NC, Kabbinavar F, Giantonio BJ, Guan ZZ, Mitchell L, Waterkamp D and Tabernero J: Efficacy and safety of bevacizumab in metastatic colorectal cancer: Pooled analysis from seven randomized controlled trials. Oncologist 18: 1004-1012, 2013

53. Galfrascoli E, Piva S, Cinquini M, Rossi A, La Verde N, Bramati A, Moretti A, Manazza A, Damia G, Torri V, et al: Risk/benefit profile of bevacizumab in metastatic colon cancer: A systematic review and meta-analysis. Dig Liver Dis 43: 286-294, 2011

54. Tahover E, Hubert A, Temper M, Salah A, Peretz T, Hamburger T and Uziely B: An observational cohort study of bevacizumab and chemotherapy in metastatic colorectal cancer patients: Safety and efficacy with analysis by age group. Target Oncol 10: 55-63, 2015.

55. Tabernero J, Hozak RR, Yoshino T, Cohn AL, Obermannova R, Bodoky G, Garcia-Carbonero R, Ciuleanu TE, Portnoy DC, Prausová J, et al: Analysis of angiogenesis biomarkers for ramucirumab efficacy in patients with metastatic colorectal cancer from RAISE, a global, randomized, double-blind,phase III study. Ann Oncol 602-609, 2018.

56. Obermannová R, Van Cutsem E, Yoshino T, Bodoky G, Prausová J, Garcia-Carbonero R, Ciuleanu T, Garcia Alfonso P, Portnoy D, Cohn A, et al: Subgroup analysis in RAISE: A randomized, double-blind phase III study of irinotecan, folinic acid, and 5-fluorouracil (FOLFIRI) plus ramucirumab or placebo in patients with metastatic colorectal carcinoma progression. Ann Oncol 27: 2082-2090, 2016.

57. Cunningham D, Lang I, Marcuello E, Lorusso V, Ocvirk J, Shin DB, Jonker D, Osborne S, Andre N, Waterkamp D, et al: Bevacizumab plus capecitabine versus capecitabine alone in elderly patients with previously untreated metastatic colorectal cancer (AVEX): An open-label, randomised phase 3 trial. Lancet Oncol 14: 1077-1085, 2013

58. Shah SR, Gressett Ussery SM, Dowell JE, Marley E, Liticker J, Arriaga Y and Verma U: Shorter bevacizumab infusions do not increase the incidence of proteinuria and hypertension. Ann Oncol 24: 960-965, 2013.

59. Li J, Qin S, Xu R, Yau TC, Ma B, Pan H, Xu J, Bai Y, Chi Y, Wang L, et al: Regorafenib plus best supportive care versus placebo plus best supportive care in Asian patients with previously treated metastatic colorectal cancer (CONCUR): A randomised, double-blind, placebo-controlled, phase 3 trial. Lancet Oncol 16: 619-629, 2015.

60. Bennouna J, Sastre J, Arnold D, Österlund P, Greil R, Van Cutsem E, von Moos R, Viéitez JM, Bouché O, Borg C, et al: Continuation of bevacizumab after first progression in metastatic colorectal cancer (ML18147): A randomised phase 3 trial. Lancet Oncol 14: 29-37, 2013

61. Hegewisch-Becker S, Graeven U, Lerchenmüller CA, Killing B, Depenbusch R, Steffens CC, Al-Batran SE, Lange T, Dietrich G, Stoehlmacher J, et al: Maintenance strategies after first-line oxaliplatin plus fluoropyrimidine plus bevacizumab for patients with metastatic colorectal cancer (AIO 0207): A randomised, non-inferiority, open-label, phase 3 trial. Lancet Oncol 16: 1355-1369, 2015.

62. Morse MA, Sun W, Kim R, He AR, Abada PB, Mynderse M and Finn RS: The role of angiogenesis in hepatocellular carcinoma Clin Cancer Res 25: 912-920, 2019.

63. Abou-Alfa GK, Meyer T, Cheng AL, El-Khoueiry AB Rimassa L, Ryoo BY, Cicin I, Merle P, Chen Y, Park JW, et al: Cabozantinib in patients with advanced and progressing hepatocellular carcinoma. N Engl J Med 379: 54-63, 2018

64. Bruix J, Qin S, Merle P, Granito A, Huang YH, Bodoky G, Pracht M, Yokosuka O, Rosmorduc O, Breder V, et al: Regorafenib for patients with hepatocellular carcinoma who progressed on sorafenib treatment (RESORCE): A randomised, double-blind, placebo-controlled, phase 3 trial. Lancet 389: 56-66, 2017.
65. Zhu AX, Park JO, Ryoo BY, Yen CJ, Poon R, Pastorelli D, Blanc JF, Chung HC, Baron AD, Pfiffer TE, et al: Ramucirumab versus placebo as second-line treatment in patients with advanced hepatocellular carcinoma following first-line therapy with sorafenib (REACH): A randomised, double-blind, multicentre, phase 3 trial. Lancet Oncol 16: 859-870, 2015.

66. Zhu AX, Kang YK, Yen CJ, Finn RS, Galle PR, Llovet JM, Assenat E, Brandi G, Pracht M, Lim HY, et al: Ramucirumab after sorafenib in patients with advanced hepatocellular carcinoma and increased $\alpha$-fetoprotein concentrations (REACH-2): A randomised, double-blind, placebo-controlled, phase 3 trial. Lancet Oncol 20: 282-296, 2019.

67. Akutsu N, Sasaki S, Takagi H, Motoya M, Shitani M, Igarashi M, Hirayama D, Wakasugi $\mathrm{H}$, Yamamoto $\mathrm{H}$, Kaneto $\mathrm{H}$, et al: Development of hypertension within 2 weeks of initiation of sorafenib for advanced hepatocellular carcinoma is a predictor of efficacy. Int J Clin Oncol 20: 105-110, 2015.

68. Llovet JM, Ricci S, Mazzaferro V, Hilgard P, Gane E, Blanc JF, de Oliveira AC, Santoro A, Raoul JL, Forner A, et al: Sorafenib in advanced hepatocellular carcinoma. N Engl J Med 359: 378-390, 2008.

69. Cheng AL,Kang YK, Chen Z, Tsao CJ, QinS,Kim JS,LuoR,Feng J, Ye S, Yang TS, et al: Efficacy and safety of sorafenib in patients in the Asia-Pacific region with advanced hepatocellular carcinoma: A phase III randomised, double-blind,placebo-controlled trial. Lancet Oncol 10: 25-34, 2009.

70. Meyer T, Fox R, Ma YT, Ross PJ, James MW, Sturgess R, Stubbs C, Stocken DD, Wall L, Watkinson A, et al: Sorafenib in combination with transarterial chemoembolisation in patients with unresectable hepatocellular carcinoma (TACE 2): A randomised placebo-controlled, double-blind, phase 3 trial. Lancet Gastroenterol Hepatol 2: 565-575, 2017.

71. Aalders KC, Tryfonidis K, Senkus E and Cardoso F: Antiangiogenic treatment in breast cancer: Facts, successes, failures and future perspectives. Cancer Treat Rev 53: 98-110, 2017.

72. Bear HD, Tang G, Rastogi P, Geyer CE Jr, Robidoux A, Atkins JN, Baez-Diaz L, Brufsky AM, Mehta RS, Fehrenbacher L, et al: Bevacizumab added to neoadjuvant chemotherapy for breast cancer. N Engl J Med 366: 310-320, 2012.

73. Miles DW, Chan A, Dirix LY, Cortes J, Pivot X, Tomczak P, Delozier T, Sohn JH, Provencher L, Puglisi F, et al: Phase III study of bevacizumab plus docetaxel compared with placebo plus docetaxel for the first-line treatment of human epidermal growth factor receptor 2-negative metastatic breast cancer. J Clin Oncol 28: 3239-3247, 2010

74. Robert NJ, Diéras V, Glaspy J, Brufsky AM, Bondarenko I, Lipatov ON, Perez EA, Yardley DA, Chan SY, Zhou X, et al: RIBBON-1: Randomized, double-blind, placebo-controlled, phase III trial of chemotherapy with or without bevacizumab for first-line treatment of human epidermal growth factor receptor 2-negative, locally recurrent or metastatic breast cancer. J Clin Oncol 29: 1252-1260, 2011.

75. Fan M, Zhang J, Wang Z, Wang B, Zhang Q, Zheng C, Li T, Ni C, Wu Z, Shao Z and Hu X: Phosphorylated VEGFR2 and hypertension: Potential biomarkers to indicate VEGF-dependency of advanced breast cancer in anti-angiogenic therapy. Breast Cancer Res Treat 143: 141-151, 2014.

76. Schneider BP, Wang M, Radovich M, Sledge GW, Badve S, Thor A, Flockhart DA, Hancock B, Davidson N, Gralow J, et al: Association of vascular endothelial growth factor and vascular endothelial growth factor receptor-2 genetic polymorphisms with outcome in a trial of paclitaxel compared with paclitaxel plus bevacizumab in advanced breast cancer: ECOG 2100. J Clin Oncol 26: 4672-4678, 2008

77. Cortes J, Calvo V, Ramírez-Merino N, O'Shaughnessy J, Brufsky A, Robert N, Vidal M, Muñoz E, Perez J, Dawood S, et al: Adverse events risk associated with bevacizumab addition to breast cancer chemotherapy: A meta-analysis. Ann Oncol 23: 1130-1137, 2012.

78. Pivot X, Schneeweiss A, Verma S, Thomssen C, Passos-Coelho JL, Benedetti G, Ciruelos E, von Moos R, Chang HT, Duenne AA and Miles DW: Efficacy and safety of bevacizumab in combination with docetaxel for the first-line treatment of elderly patients with locally recurrent or metastatic breast cancer: Results from AVADO. Eur J Cancer 47: 2387-2395, 2011.

79. Rini BI, Powles T, Atkins MB, Escudier B, McDermott DF, Suarez C, Bracarda S, Stadler WM, Donskov F, Lee JL, et al: Atezolizumab plus bevacizumab versus sunitinib in patients with previously untreated metastatic renal cell carcinoma (IMmotion151): A multicentre, open-label, phase 3, randomised controlled trial. Lancet 393: 2404-2415, 2019. 
80. Yang L, Chen Y, Qin S, Wang L, Hua H, Liu X, et al: Clinical observation on hypertenison induced by anti-angiogenic agents for cancer. Chin Clin Oncol 19: 603-607, 2014.

81. Yang WY, Melgarejo JD, Thijs L, Zhang ZY, Boggia J, Wei FF, Hansen TW, Asayama K, Ohkubo T, Jeppesen J, et al: Association of office and ambulatory blood pressure with mortality and cardiovascular outcomes. JAMA 322: 409-420, 2019.

82. Choueiri TK, Vaziri SAJ, Jaeger E, Elson P, Wood L, Bhalla IP, Small EJ, Weinberg V, Sein N, Simko J, et al: von Hippel-Lindau gene status and response to vascular endothelial growth factor targeted therapy for metastatic clear cell renal cell carcinoma. J Urol 180: 860-866, 2008

83. Li Y, Li S, Zhu Y, Liang X, Meng H, Chen J, Zhang D, Guo H and Shi B: Incidence and risk of sorafenib-induced hypertension: A systematic review and meta-analysis. J Clin Hypertens (Greenwich) 16: 177-185, 2014.

84. Frey MK, Dao F, Olvera N, Konner JA, Dickler MN and Levine DA: Genetic predisposition to bevacizumab-induced hypertension. Gynecol Oncol 147: 621-625, 2017.

85. Scagliotti GV, Krzakowski M, Szczesna A, Strausz J, Makhson A, Reck M, Wierzbicki RF, Albert I, Thomas M, Miziara JE, et al: Sunitinib plus erlotinib versus placebo plus erlotinib in patients with previously treated advanced non-small-cell lung cancer: A phase III trial. J Clin Oncol 30: 2070-2078, 2012.

86. Shen L, Li J, Xu J, Pan H, Dai G, Qin S, Wang L, Wang J, Yang Z, Shu Y, et al: Bevacizumab plus capecitabine and cisplatin in Chinese patients with inoperable locally advanced or metastatic gastric or gastroesophageal junction cancer: Randomized, double-blind, phase III study (AVATAR study). Gastric Cancer 18: 168-176, 2015.

87. Schwartzberg LS, Tauer KW, Hermann RC, Makari-Judson G, Isaacs C, Beck JT, Kaklamani V, Stepanski EJ, Rugo HS, Wang W, et al: Sorafenib or placebo with either gemcitabine or capecitabine in patients with HER-2-negative advanced breast cancer that progressed during or after bevacizumab. Clin Cancer Res 19: 2745-2754, 2013.
88. Crown JP, Diéras V, Staroslawska E, Yardley DA, Bachelot T, Davidson N, Wildiers H, Fasching PA, Capitain O, Ramos M, et al: Phase III trial of sunitinib in combination with capecitabine versus capecitabine monotherapy for the treatment of patients with pretreated metastatic breast cancer. J Clin Oncol 31: 2870-2878, 2013.

89. Syrigos KN, Karapanagiotou E, Boura P, Manegold C and Harrington K: Bevacizumab-induced hypertension: Pathogenesis and management. BioDrugs 25: 159-169, 2011.

90. Williams B, Mancia G, Spiering W, Agabiti Rosei E, Azizi M, Burnier M, Clement DL, Coca A, de Simone G, Dominiczak A, et al: $2018 \mathrm{ESC} / \mathrm{ESH}$ guidelines for the management of arterial hypertension. Eur Heart J 39: 3021-3104, 2018.

91. Maitland ML, Bakris GL, Black HR, Chen HX, Durand JB, Elliott WJ, Ivy SP, Leier CV, Lindenfeld J, Liu G, et al: Initial assessment, surveillance, and management of blood pressure in patients receiving vascular endothelial growth factor signaling pathway inhibitors. J Natl Cancer Inst 102: 596-604, 2010.

(i) $\Theta$ This work is licensed under a Creative Commons

cc) Attribution-NonCommercial-NoDerivatives 4.0 International (CC BY-NC-ND 4.0) License. 